Revista Mídia e Cotidiano

ISSN: 2178-602X

Artigo Seção Temática

Volume 15, Número 2, maio/ago. de 2021

Submetido em: 22/02/2021

Aprovado em: 21/04/2021

\title{
A imagem é clara? O VAR e as interpretações da imagem na Copa do Mundo da Rússia 2018
}

\section{Is the image clear enough? The VAR and the images' interpretations in the 2018 FIFA World Cup Russia}

\section{¿Es clara la imagen? VAR e interpretaciones de la imagen en la Copa Mundial de la FIFA Rusia 2018}

\author{
Carlos Roberto Gaspar TEIXEIRA ${ }^{1}$ \\ Roberto TIETZMANN ${ }^{2}$
}

\begin{abstract}
Resumo
Esse artigo analisa as transmissões de dois lances polêmicos com árbitro de vídeo em dois jogos da seleção brasileira durante a Copa do Mundo FIFA 2018 na Rússia, em que uma única geração oficial dos vídeos das partidas motivou interpretações divergentes de comentaristas na televisão aberta e por assinatura. Questionamos o motivo das discordâncias continuadas apesar do aprimoramento de tecnologia e regulamento. Fundamentado em pensadores de teorias da imagem, como Badiou (2017), Bergson (2006), Didi-Huberman (1998) e Debray (1993), os autores puderam concluir que toda a imagem é dotada de um carácter interpretativo e subjetivo, o que raramente a permite ser indiscutível, em se tratando de esporte, mais especificamente no futebol.
\end{abstract}

Palavras-chave: Imagem. Esporte. Árbitro de vídeo. Copa do Mundo.

\begin{abstract}
This article analyzes the broadcast of two controversial moves involving a video referee in two matches played by the Brazilian soccer team during the 2018 FIFA World Cup in Russia. A single official video feed generated divergent interpretations by commentators on broadcast and subscription-based television. We question the reason for continued disagreements despite the improvements in technology and rules. Based on image theorists as Badiou (2017), Bergson (2006), Didi-Huberman (1998), and Debray (1993),
\end{abstract}

\footnotetext{
1 Doutorando em Comunicação Social pela PUCRS na Escola de Comunicação, Artes e Design FAMECOS. E-mail: eu@ ocarlosteixeira.com.br. ORCID: 0000-0001-6829-1682.

${ }^{2}$ Doutor em Comunicação Social pela Pontifícia Universidade Católica do Rio Grande do Sul. Mestre em Comunicação Social pela Pontifícia Universidade Católica do Rio Grande do Sul. Professor Adjunto dos Programas de Pós-Graduação em Comunicação Social e Escrita Criativa. Coordenador do grupo de pesquisa ViDiCa - Cultura Audiovisual Digital. E-mail: rtietz@ pucrs.br. ORCID: 0000-0002-8270-0865.
} 
the authors conclude that every image has an interpretative and a subjective character, which rarely allows it to be indisputable when it comes to sport, specifically in soccer.

Keywords: Image. Sport. Video referee. World Cup.

\section{Resumen}

Este artículo analiza las transmisiones de dos jugadas controvertidas con el uso del árbitro de video en dos partidos de la selección brasileña durante la Copa Mundial de la FIFA Rusia 2018, donde una sola generación oficial de los videos del partido ha motivado interpretaciones divergentes por parte de comentaristas de televisión abierta y paga. Cuestionamos el motivo de los continuos desacuerdos a pesar de la mejora de la tecnología y la regulación. Partiendo de pensadores de las teorías de la imagen, como Badiou (2017), Bergson (2006), Didi-Huberman (1998) y Debray (1993), se pudo concluir que la imagen en su conjunto está dotada de un carácter interpretativo y subjetivo, que pocas veces permite que sea indiscutible, cuando se trata de deporte, más concretamente en fútbol.

Palabras clave: Imagen. Deporte. Árbitro de video. Copa Mundial.

\section{Introdução: o VAR e a análise de imagens na Copa do Mundo}

Realizada desde 1930, a Copa do mundo de Futebol da FIFA apresenta um histórico rico em polêmicas de arbitragem ao longo de suas 21 edições. Salgado (2014) elencou alguns erros de juízes que marcaram essa história: na final de 1966 a Inglaterra teve um gol que não ultrapassou a linha validado; vinte anos depois, contra a Inglaterra, Maradona com a mão fez o famoso gol que classificou os argentinos para a semifinal; na Copa de 2002, o juiz marcou um pênalti no atacante brasileiro Luizão, mesmo tendo sido derrubado fora da área; em 2010 a Inglaterra não teve um gol legal assinalado em um chute que a bola entrou. Exemplos de erros não faltam, tanto em campeonatos mundiais quanto em outras diversas partidas e competições.

$\mathrm{Na}$ busca de reduzir, ou até mesmo acabar, com erros como esses, surgiu nos últimos anos uma das grandes novidades no futebol: a implementação do árbitro assistente de vídeo (VAR - video assistant referee). No início de sua implementação, a utilização do VAR dividiu opiniões. Em sua estreia oficial no mundial de clubes em 2016, o árbitro de vídeo causou muita discussão. O primeiro lance em que o VAR foi acionado foi um pênalti legal que o árbitro de campo não viu, tendo sido marcado após análise de vídeo. Entretanto, no início da jogada, houve um impedimento não assinalado. Segundo 


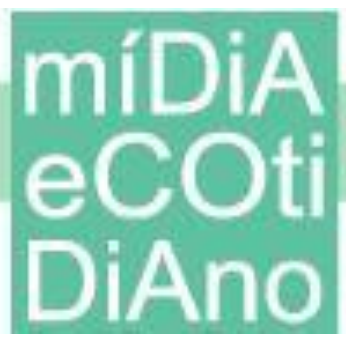

a Revista Veja (2016), "Até mesmo os principais comentaristas de arbitragem divergiram" sobre o lance. A matéria (ibidem) cita que o ex-juiz Carlos Eugênio Simon, da emissora Fox Sports, considerou que o pênalti foi bem marcado, entendendo que o impedimento não deveria mesmo ser assinalado. Arnaldo Cézar Coelho, da Rede Globo, viu impedimento no lance e considerou um erro grave do árbitro de vídeo. Após a estreia, as polêmicas acerca do VAR continuaram mundo afora, "Itália, Alemanha e Portugal começaram a adotar o uso da tecnologia [...], mas não existe ainda consenso em relação às chances de sucesso" (GAÚCHA ZH, 2017). A referida matéria cita que em Portugal os jornalistas divergiram sobre a utilização do árbitro de vídeo, na Itália o tempo para análise do vídeo e tomada de decisão era questionado por parte da mídia, a Alemanha sofreu com problemas tecnológicos nas transmissões e alguns árbitros sugeriram retirar os recursos de assistente de vídeo caso estes não fossem melhorados, já nos Estados Unidos não houve muitos problemas, dando a entender que a utilização era viável e dava continuidade a uma tradição do uso de recurso semelhante no futebol americano. No início de 2018, a Confederação Brasileira de Futebol vetou o uso do VAR no Campeonato Brasileiro, em votação entre os clubes participantes, 12 dos 20 integrantes foram contra o recurso (ESPN, 2018).

Em março de 2018, durante a Reunião Geral Anual da Associação de Futebol, a utilização do árbitro de vídeo na Copa do Mundo foi aprovada por unanimidade (FIFA, 2018b). Um estudo com a duração de um ano entregue à mídia e revelou que o VAR foi utilizado por mais de 20 associações e competições em 972 partidas oficiais e 693 amistosos, treinamentos e competições não oficiais por todo o mundo. Os resultados apresentados no relatório revelaram que a precisão das decisões passíveis de revisão aumentou de 5,8\% para 98,8\% (FIFA, 2018d).

Este artigo propõe uma análise sobre a questão da imagem e sua interpretação, tendo como objetivo compreender os possíveis motivos que fomentam opiniões divergentes sobre uma mesma imagem. Para isso serão analisadas algumas manifestações midiáticas sobre lances polêmicos relacionando-as com teorias da imagem. Como proposta metodológica foram coletadas as opiniões manifestadas em duas transmissões de dois lances polêmicos em jogos da seleção brasileira de futebol masculino, com as percepções da equipe de comentaristas, buscando-se então resgatar autores clássicos das 


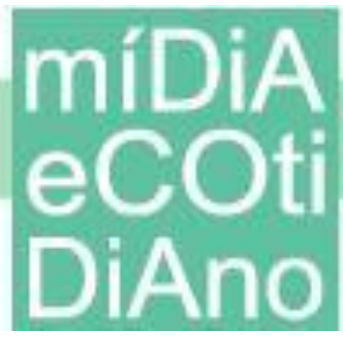

teorias da imagem para contribuir em um entendimento da complexidade presente na interpretação visual.

\section{As polêmicas da imagem nos jogos da seleção brasileira}

De acordo com o site oficial da FIFA (FIFA, 2018c), a equipe do VAR é composta por quatro integrantes: um árbitro principal de vídeo e mais três assistentes. Durante a Copa do Mundo na Rússia esta equipe ficou localizada no International Broadcast Centre (IBC) em Moscou, contando com mais de 33 câmeras, oito delas com super slow-motion e quatro com ultra slow-motion. A entidade (ibidem) afirmou que:

[...] os recursos de câmera lenta são usados para identificar pontos de contatos físicos ou posições irregulares, já a velocidade normal é utilizada para julgamentos subjetivos, por exemplo, a intensidade de um ataque ou para determinar se um toque de mão foi deliberado ${ }^{3}$.

O juiz de vídeo apoia a tomada de decisão do árbitro de campo comunicando-se via rádio em situações de revisão de campo para interpretação, penalidades, cartões ou impedimentos. Existem dois tipos de revisões de jogadas com o VAR: 1) revisão oficial, quando o árbitro é avisado de um lance e se dirige a uma área marcada que contém um televisor para que o incidente seja revisado; ou 2) mão no ouvido, quando o árbitro atrasa a reinicialização do jogo a qualquer momento para se comunicar com o VAR, esse não sendo considerado pela FIFA uma revisão oficial (FIFA, 2018c).

Com a implementação da análise de imagens durante as partidas da Copa do Mundo, seu impacto foi rapidamente notado. Na primeira fase da competição, o árbitro de vídeo foi usado 335 vezes em 48 partidas, sendo que 17 dessas ocorrências foram examinadas por meio da revisão oficial, com 14 decisões modificadas durante o jogo (EXAME, 2018). A fase de grupos também teve um recorde de pênaltis marcados, com 24 ao total. A questão que permanece em aberto é o quanto a utilização das imagens de vídeo pelo VAR auxilia na dissolução de problemas de arbitragem no futebol. Apesar de um suposto consenso sobre a implementação da análise de imagens para amparar os juízes

\footnotetext{
3 Traduzido pelos autores: Slow motion replays are mainly used for factual situations, for example, to identify the point of contact of a physical offence or the position of an offence. Normal speed is used for subjective judgments, for example, the intensity of an offence or to determine if a handball was deliberate.
} 


\section{míDiA

na tomada de decisão durante as partidas, existe um ambiente de incerteza, principalmente na mídia, em relação ao quanto realmente o vídeo está ajudando na resolução das polêmicas futebolísticas com a arbitragem.

Ao final da fase de grupos da Copa do Mundo 2018, chamou a atenção a quantidade de citações e discussões oriundas das polêmicas envolvendo arbitragem e análise de vídeo observadas de maneira não sistematizada na imprensa e redes sociais. Quando se observam especificamente as partidas disputadas pela seleção brasileira, dois dos três jogos da primeira fase apresentaram lances polêmicos, em que as emissoras e programas esportivos brasileiros debateram incessantemente as imagens, questionando as decisões da arbitragem. Na estreia do Brasil, dia 17 de junho de 2018 no jogo contra a Suíça, o gol de empate dos europeus originou reclamações de falta no lance, agravadas porque a equipe de arbitragem optou por não analisar as imagens de forma oficial. $\mathrm{Na}$ partida de 22 de junho contra a Costa Rica, após marcar um pênalti em Neymar, o juiz foi orientado pelo VAR a rever o vídeo do lance, o que resultou na anulação da marcação a favor do time brasileiro. O que vale ser destacado nesses acontecimentos são as diferentes opiniões das mais diversas partes envolvidas no processo: jogadores, técnicos, árbitros, narradores, comentaristas, concordando ou discordando do que aparentemente muitos alegaram ser "imagens claras".

Para a análise dessas manifestações escolhemos duas transmissões veiculadas pela Rede Globo, grupo de mídia brasileiro que detinha os direitos televisivos da Copa do Mundo. Foi considerado determinante para esta escolha o fato da empresa gerar duas transmissões separadas em canais diferentes: na televisão aberta pela TV Globo e em suas afiliadas e na televisão por assinatura no canal SporTV. Assim, foram coletadas as partidas na íntegra ${ }^{4}$ e selecionados somente os momentos dos dois principais lances polêmicos das partidas da seleção brasileira e seus desdobramentos subsequentes, exclusivamente os que ocorreram durante a transmissão ao vivo: o gol da Suíça (jogo 1) e o pênalti em Neymar (jogo 2).

\footnotetext{
${ }^{4}$ Os videoteipes das partidas na íntegra foram obtidos por meio dos aplicativos Globoplay, disponível em: https://globoplay.globo.com e Globosat Play, disponível em: https://globosatplay.globo.com/sportv. Acesso em: 1 jul. 2018.
} 
Os vídeos coletados foram tabulados (quadros 1 e 2) seguindo critérios considerados relevantes para a análise. Os desdobramentos dos lances foram separados de acordo com os replays apresentados na transmissão, onde em cada um deles foram verificados fatores que de algum modo implicam na percepção e interpretação das imagens, bem como o comentário durante aquela reprodução específica:

1) Plano da filmagem: o plano foi definido pelo enquadramento e distância do lance, assim como pela posição da câmera em relação ao lance que estava sendo mostrado.

2) Velocidade do replay: conforme já citado a própria FIFA menciona que existem dois tipos de câmeras lentas para análise do VAR: super slow-motion e ultra slow-motion. Tendo em vista a dificuldade de diferenciar as velocidades de reprodução dos vídeos, se estabeleceu apenas uma separação entre uma velocidade próxima ao considerado normal (Normal) e aqueles que apresentaram uma lentidão facilmente identificada (Câmera lenta).

3) Tempo: foi contado de forma aproximada o intervalo entre a exibição de cada novo replay, visto que as repetições são mostradas diversas vezes após o acontecimento durante a transmissão ao vivo.

4) Comentário: conforme cada replay era apresentado, se registrou os comentários da equipe de transmissão, que repercutia e argumentava sobre suas percepções dos lances: tendo os narradores $(N)$ e os comentaristas $(C)$.

Os quadros 1 e 2 apresentam a tabulação final da transmissão dos dois lances que permitiram observações acerca dos comentários manifestados. É importante frisar que todas as imagens oficiais das partidas são fornecidas pelo IBC (International Broadcast Centre) da FIFA. Dali foi gerado o sinal único de transmissão para todos os 64 jogos, processado, monitorado e transmitido para TVs, rádios e dispositivos digitais em 219 territórios em todo o mundo (FIFA, 2018a). Sendo assim, as imagens ao vivo das partidas, assim como os cortes, trocas de câmeras, replays etc. são iguais em todas as transmissões, o que facilitou a comparação das reações, interpretações e percepções de cada um dos canais. 
Quadro 1 - Brasil x Suíça: Gol da Suíça

\begin{tabular}{|c|c|c|c|c|c|}
\hline & Plano & $\begin{array}{l}\text { Veloci- } \\
\text { dade }\end{array}$ & Tempo & Comentários - GLOBO & Comentários - SPORTV \\
\hline GGOL & Padrão & Normal & $\begin{array}{c}4: 29 \\
2^{0} \\
\text { tempo }\end{array}$ & $\begin{array}{l}\text { "Subiu sozinho no meio da área. Deu } \\
\text { bobeira defesa brasileira, Alisson não } \\
\text { sai" - Galvão Bueno }(\mathrm{N})\end{array}$ & $\begin{array}{l}\text { "Na cobrança de escanteio } \\
\text { ele subiu praticamente } \\
\text { sozinho na área brasileira" - } \\
\text { Milton Leite }(\mathrm{N})\end{array}$ \\
\hline $\begin{array}{c}\text { Replay } \\
1\end{array}$ & Aéreo & Normal & $\begin{array}{r}+29 \\
\text { seg }\end{array}$ & $\begin{array}{l}\text { "Número } 14 \text { vem lá sozinho dentro da } \\
\text { pequena área" - Galvão Bueno }(\mathrm{N})\end{array}$ & $\begin{array}{l}\text { "Repare como ele chega no } \\
\text { meio da pequena área..." - } \\
\text { Milton Leite }(\mathrm{N})\end{array}$ \\
\hline $\begin{array}{l}\text { Replay } \\
\quad 2\end{array}$ & $\begin{array}{l}\text { Fechado } \\
\text { Frontal }\end{array}$ & $\begin{array}{l}\text { Câmera } \\
\text { lenta }\end{array}$ & $+6 \mathrm{seg}$ & $\begin{array}{l}\text { "Ninguém subiu, a defesa toda ficou } \\
\text { parada" - Casagrande }(C)\end{array}$ & $\begin{array}{l}\text { "[...] não tem ninguém } \\
\text { marcando ele. Ele sobe } \\
\text { sozinho pra desviar..." - } \\
\text { Milton Leite }(\mathrm{N})\end{array}$ \\
\hline $\begin{array}{c}\text { Replay } \\
3\end{array}$ & $\begin{array}{l}\text { Close } \\
\text { Frontal }\end{array}$ & $\begin{array}{l}\text { Câmera } \\
\text { lenta }\end{array}$ & +8 seg & $\begin{array}{l}\text { "Olha lá! Opa Arnaldo!" - Galvão Bueno } \\
\text { (N) } \\
\text { "Falta! Gol irregular" - Arnaldo C. } \\
\text { Coelho (C) }\end{array}$ & $\begin{array}{l}\text { "Ele dá uma empurradinha } \\
\text { ali hein!" - Milton }(\mathrm{N}) \\
\text { "De leve uma } \\
\text { empurradinha..." - Maurício } \\
\text { Noriega }(\mathrm{C})\end{array}$ \\
\hline $\begin{array}{c}\text { Replay } \\
\quad 4\end{array}$ & $\begin{array}{l}\text { Fechado } \\
\text { Câmera } \\
\text { atrás do } \\
\text { gol }\end{array}$ & $\begin{array}{l}\text { Câmera } \\
\text { lenta }\end{array}$ & +9 seg & $\begin{array}{l}\text { "Estão reclamando para chamar o } \\
\text { árbitro de vídeo" - Galvão Bueno (N) e } \\
\text { Arnaldo C. Coelho (C) } \\
\text { "Seu juiz vai olhar! Para que que tem } \\
\text { árbitro de vídeo? Tem que olhar! É a } \\
\text { desmoralização do árbitro de vídeo" - } \\
\text { Galvão Bueno (N) } \\
\text { "O italiano (VAR) tinha que ter falado, } \\
\text { que já tinha dado o tempo dele ver que } \\
\text { houve o empurrão" - Arnaldo C. Coelho } \\
\text { (C) } \\
\text { "Muito estranho ninguém ter subido. Era } \\
\text { exatamente o Miranda que tinha que } \\
\text { subir, foi empurrado com as duas mãos } \\
\text { nas costas pelo Zuber. Eu estou } \\
\text { dizendo que esse negócio de árbitro de } \\
\text { vídeo, isso vai dar lambança na Copa } \\
\text { do Mundo..." - Galvão Bueno (N) }\end{array}$ & $\begin{array}{l}\text { "Mas o pior de tudo isso aí é } \\
\text { o erro de posicionamento da } \\
\text { defesa brasileira [...] Há } \\
\text { reclamação dos jogadores } \\
\text { brasileiros de um empurrão } \\
\text { aí, mas não sei se foi um } \\
\text { empurrão tão escandaloso } \\
\text { para o gol ser anulado" - } \\
\text { Maurício Noriega (C) } \\
\text { "Claro que o empurrão } \\
\text { aconteceu, agora ele não foi } \\
\text { determinante pro gol, erro de } \\
\text { posicionamento" - Lédio } \\
\text { Carmona (C) }\end{array}$ \\
\hline \multicolumn{6}{|c|}{ JOGO REINICIADO SEM REVISÃO DO VAR - 1 minutos e 17 segundos após o gol } \\
\hline $\begin{array}{c}\text { Replay } \\
\quad 5\end{array}$ & $\begin{array}{l}\text { Fechado } \\
\text { Frontal }\end{array}$ & $\begin{array}{l}\text { Câmera } \\
\text { lenta }\end{array}$ & $\begin{array}{l}+3 \\
\min \end{array}$ & $\begin{array}{l}\text { "Alguma dúvida Arnaldo?" - Galvão } \\
\text { Bueno (N) } \\
\text { "Nenhuma dúvida! É claro o árbitro } \\
\text { tinha que ter visto! Isso não é nem para } \\
\text { árbitro de vídeo, é para o árbitro } \\
\text { mesmo! Não prestou atenção, falha } \\
\text { grosseira" - Arnaldo C. Coelho (C) } \\
\text { "Passou no telão, ele não precisava } \\
\text { nem ir na telinha na lateral de campo, } \\
\text { estava passando no telão" - Galvão } \\
\text { Bueno (N) }\end{array}$ & --- \\
\hline $\begin{array}{c}\text { Replay } \\
6\end{array}$ & $\begin{array}{l}\text { Câmera } \\
\text { de dentro } \\
\text { do gol }\end{array}$ & Normal & $\begin{array}{l}+1 \mathrm{~min} \\
32 \mathrm{seg}\end{array}$ & $\begin{array}{l}\text { "O gol foi irregular, o atante empurrou o } \\
\text { Miranda" - Casagrande (C) }\end{array}$ & --- \\
\hline $\begin{array}{c}\text { Replay } \\
7\end{array}$ & $\begin{array}{l}\text { Close } \\
\text { Frontal }\end{array}$ & $\begin{array}{l}\text { Câmera } \\
\text { lenta }\end{array}$ & +6 seg & $\begin{array}{l}\text { "Ele estava nas costas do Miranda, ele } \\
\text { empurrou" - Casagrande (C) }\end{array}$ & $\begin{array}{l}\text { "Você viu ali? A reclamação } \\
\text { de todos os brasileiros, agora } \\
\text { deu para ver o replay com o } \\
\text { Alisson reclamando" - Milton } \\
\text { Leite. }\end{array}$ \\
\hline
\end{tabular}

Fonte: Elaborado pelos autores a partir das transmissões Globo e SporTV. 
Quadro 2 - Brasil x Costa Rica: Pênalti em Neymar

\begin{tabular}{|c|c|c|c|c|c|}
\hline & Plano & $\begin{array}{l}\text { Veloci- } \\
\text { dade }\end{array}$ & Tempo & GLOBO & SPORTV \\
\hline PÊNALTI & Padrão & Normal & $\begin{array}{l}32: 23 \\
2^{\circ} \\
\text { tempo }\end{array}$ & $\begin{array}{l}\text { "Olha a chance! Puxou, caiu... O juiz } \\
\text { deu pênalti. É pênalti para o Brasil! [...] } \\
\text { Está tendo uma checagem..." - Galvão } \\
\text { Bueno }(\mathrm{N})\end{array}$ & $\begin{array}{l}\text { "É pênalti! Neymar puxado [...]. Os jogadores } \\
\text { da Costa Rica se desesperam, mas o puxão } \\
\text { pareceu claro." - Luiz Roberto (N) } \\
\text { "Se puxou, e eu acho que ele puxou mesmo, } \\
\text { tem que dar cartão amarelo pro jogador da } \\
\text { Costa Rica também" - Lédio Carmona (C) }\end{array}$ \\
\hline Replay 1 & $\begin{array}{l}\text { Aberto } \\
\text { por trás }\end{array}$ & $\begin{array}{l}\text { Câmera } \\
\text { lenta }\end{array}$ & +22 seg & $\begin{array}{l}\text { "Vamos rever, atenção! Arnaldo Cezar } \\
\text { Coelho!" - Galvão Bueno (N) }\end{array}$ & $\begin{array}{l}\text { "Vamos ver! Braço do Gonzales" - Luiz } \\
\text { Roberto (N) }\end{array}$ \\
\hline Replay 2 & $\begin{array}{l}\text { Fechado } \\
\text { Lateral }\end{array}$ & $\begin{array}{l}\text { Câmera } \\
\text { lenta }\end{array}$ & $+5 \mathrm{seg}$ & $\begin{array}{l}\text { "[...] o braço esquerdo do zagueiro veja } \\
\text { só, ele impede que o Neymar ao driblar } \\
\text { continue na jogada. Pênalti claro!" - } \\
\text { Arnaldo C. Coelho }(\mathrm{C}) \\
\text { "Esse gesto exagerado que leva... o juiz } \\
\text { vai ver no vídeo" - Galvão Bueno (N) }\end{array}$ & $\begin{array}{l}\text { "Por esse ângulo... Neymar dá uma } \\
\text { amplificada... Valorizou o Neymar e o juiz } \\
\text { deu. Será que ele vem ver no vídeo?" - Luiz } \\
\text { Roberto (N) } \\
\text { "Não fica claro o puxão, fica claro uma ação } \\
\text { com a mão direita, mas o puxão não" - Lédio } \\
\text { Carmona (C) }\end{array}$ \\
\hline \multicolumn{6}{|c|}{ APÓS INTERVENÇÃO DO VAR O JUIZ VAI CONSULTAR O VÍDEO - 55 segundos depois da marcação } \\
\hline $\begin{array}{l}\text { Replay } 3 \\
\quad(2 x)\end{array}$ & $\begin{array}{l}\text { Aberto } \\
\text { Frontal }\end{array}$ & Normal & $+31 \mathrm{seg}$ & $\begin{array}{l}\text { "Esse gesto exagerado de abrir os } \\
\text { braços é que acaba criando isso" } \\
\text { Vamos ver? Olha lá!" - Galvão Bueno } \\
\text { (N) }\end{array}$ & $\begin{array}{l}\text { "Há o toque na barriga do Neymar... Vamos } \\
\text { ver o que o juiz vai fazer?" - Luiz Roberto }(\mathrm{N})\end{array}$ \\
\hline \multicolumn{4}{|c|}{$\begin{array}{l}\text { JUIZ ANULA A MARCAÇÃO DO PÊNALTI - } \\
\text { após } 20 \text { segundos analisando as imagens }\end{array}$} & $\begin{array}{l}\text { "Essa mão do zagueiro na barriga do } \\
\text { Neymar quando ele dribla pronto para } \\
\text { chutar em gol não é considerado } \\
\text { pênalti?" - Arnaldo C. Coelho (C) }\end{array}$ & $\begin{array}{l}\text { "Não, ele não confirma o pênalti" - Luiz } \\
\text { Roberto }(\mathrm{N}) \\
\text { "Está certo o árbitro não foi pênalti." - Lédio } \\
\text { Carmona }(\mathrm{C}) \\
\text { "Valoriza muito o Neymar" - Luiz Roberto }(\mathrm{N}) \\
\text { "Parecia um puxão, mas não aconteceu o } \\
\text { puxão. Foi simulação do Neymar" - Lédio } \\
\text { Carmona }(\mathrm{C}) \\
\text { "Quando ele percebe o toque na barriga ele } \\
\text { se joga para trás" - Luiz Roberto }(\mathrm{N})\end{array}$ \\
\hline Replay 4 & $\begin{array}{l}\text { Fechado } \\
\text { Frontal }\end{array}$ & $\begin{array}{l}\text { Câmera } \\
\text { lenta }\end{array}$ & $+23 \mathrm{seg}$ & $\begin{array}{l}\text { O replay inicia numa velocidade bem } \\
\text { lenta e repentinamente é cortado, } \\
\text { aparentemente pareceu um erro na } \\
\text { transmissão. }\end{array}$ & \\
\hline Replay 5 & $\begin{array}{l}\text { Aberto } \\
\text { Frontal }\end{array}$ & $\begin{array}{l}\text { Câmera } \\
\text { lenta }\end{array}$ & $\begin{array}{l}+3 \min \\
\text { e } 5 \text { seg }\end{array}$ & --- & $\begin{array}{l}\text { "De novo o lance aí Ricardinho!" - Luiz } \\
\text { Roberto (N) }\end{array}$ \\
\hline Replay 6 & $\begin{array}{l}\text { Close } \\
\text { frontal }\end{array}$ & $\begin{array}{l}\text { Câmera } \\
\text { lenta }\end{array}$ & $+7 \mathrm{seg}$ & --- & $\begin{array}{l}\text { "Depois que o jogador da Costa Rica solta, aí } \\
\text { ele se joga pra trás" - Luiz Roberto }(\mathrm{N})\end{array}$ \\
\hline Replay 7 & $\begin{array}{l}\text { Fechado } \\
\text { Frontal }\end{array}$ & $\begin{array}{l}\text { Câmera } \\
\text { lenta }\end{array}$ & $+5 \mathrm{seg}$ & $\begin{array}{l}\text { "Olha lá Arnaldo!" - Galvão Bueno (N) } \\
\text { "Se ele não tivesse valorizado, o juiz } \\
\text { daria o pênalti. Porque aquela mão } \\
\text { esquerda dele na barriga impedindo } \\
\text { depois do drible ele sair... É que foi uma } \\
\text { valorizada, mas aquela mão esquerda } \\
\text { quando ele limpou a jogada e depois o } \\
\text { zagueiro esconde a mão esquerda para } \\
\text { dizer que não fez nada [...] Agora, se ele } \\
\text { está valorizando e o árbitro por causa } \\
\text { da valorização não deu pênalti, são } \\
\text { outros } 500 \text { " Arnaldo C. Coelho (C) } \\
\text { "Eu acho que foi pênalti, um toque } \\
\text { daquele dentro da área determina muito. } \\
\text { Ele estava armando para chutar e de } \\
\text { repente não pode mais armar para } \\
\text { chutar. No vídeo não dá para mensurar } \\
\text { a força que o cara põe. Para mim pênalti } \\
\text { claro." - Ronaldo (C) }\end{array}$ & $\begin{array}{l}\text { "Talvez ele conseguisse até seguir no lance" } \\
\text { - Luiz Roberto (N) }\end{array}$ \\
\hline
\end{tabular}

Fonte: Elaborado pelos autores a partir das transmissões Globo e SporTV. 
É importante destacar uma diferença entre a experiência do árbitro e dos telespectadores. Nas transmissões, o replay sempre é apresentado logo após ocorrer o lance, enquanto o árbitro em campo tem de tomar uma decisão imediatamente. Esta "visão privilegiada" propiciada pela televisão teve efeitos nas falas dos comentaristas. Observouse que, durante as transmissões, os questionamentos só iniciaram depois dos replays. Ao narrarem o desenrolar da partida, a tendência dos narradores foi de fazer um relato acrítico, sem inicialmente questionar ou apontar anormalidades nas marcações do juiz. No quadro 1, a primeira constatação unânime na transmissão foi o fato do jogador aparecer sozinho dentro da área brasileira, quando até então nenhuma irregularidade fora apontada.

Com a repetição das imagens, as opiniões começaram a divergir. Após o terceiro replay, com um close frontal em câmera lenta, os questionamentos emergiram. Foi possível verificar a dissonância existente entre os comentários realizados pela equipe da televisão aberta em relação aos profissionais do canal pago. Na TV Globo, todos os componentes da bancada foram taxativos, utilizando expressões como: "nenhuma dúvida", "o atacante empurrou", "foi empurrado com as duas mãos nas costas". Na SporTV, havia dúvidas se a intensidade foi suficiente para a marcação da falta. Exemplos de comentários incluíram: "de leve uma empurradinha", "não sei se foi um empurrão tão escandaloso", “o empurrão aconteceu, agora ele não foi determinante para o gol”. Na transmissão aberta, ocorreram contestações do porquê o vídeo não ter sido analisado pelo árbitro principal, chegando a afirmações como: "É a desmoralização do árbitro de vídeo", enquanto no canal pago em nenhum momento foi manifestada qualquer consideração a respeito do uso oficial do VAR.

O segundo lance (quadro 2) teve um início similar ao primeiro, em que a marcação do árbitro não foi questionada antes da repetição. A percepção inicial foi de pênalti, entretanto, conforme os replays foram reproduzidos, a divergência e as dúvidas começaram igualmente a aparecer. Em ambos os canais foi mencionado o exagero e amplificação do movimento por parte do atacante, sugerindo uma tentativa de intensificação da infração. Cabe frisar que as opiniões foram manifestadas, novamente, somente depois da reprodução em câmera lenta. Mais uma vez, houve discordância nos comentários, sendo o ponto principal das análises a interpretação da intenção do atacante em valorizar o lance. Para a equipe da Globo, o lance foi claro, independente da 


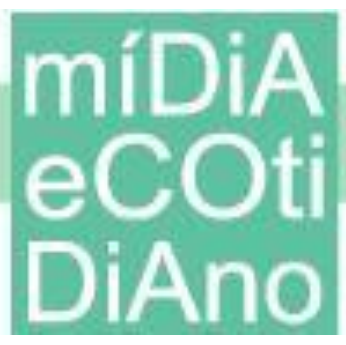

amplificação do movimento do atacante: "Pênalti claro", "se ele está valorizando e o árbitro por causa da valorização não deu pênalti, são outros 500”. Por sua vez, os comentaristas da SporTV discordaram das percepções observadas na Rede Globo: "Está certo o árbitro, não foi pênalti", "foi simulação de Neymar", "ele se joga para trás", "talvez ele conseguisse até seguir no lance". Chama a atenção um comentário feito pelo ex-jogador Ronaldo Nazário na Globo: "No vídeo não dá para mensurar a força que o cara põe", sendo esse um dos raros momentos durante as transmissões ao vivo que o viés interpretativo da análise de imagens foi supostamente questionado.

Essas constatações motivam uma reflexão a respeito do quanto uma imagem pode ser interpretada subjetivamente por seus espectadores, mesmo que sejam comentaristas profissionais. Ao averiguar a discrepância das opiniões a partir da repetição da exibição dos dois lances, foi possível estabelecer relações com pensadores clássicos das teorias da imagem. Para isso foram definidas neste texto duas perspectivas: a) o processo de interpretação das imagens ocorre de forma complexa e individualizada; b) seriam as imagens realmente capazes de representar o real?

\section{Resgatando pensadores clássicos das teorias da imagem para explicar a divergência de percepções dos lances}

A ontologia da imagem é amplamente discutida em diversas obras clássicas. Os desdobramentos perceptivos acerca da imagem vêm sendo analisados por inúmeros autores, filósofos e pensadores. Muitos deles refletem sobre os modos de interpretação e o poder de representação do real que as imagens têm. Uma possível intersecção entre as diversas vertentes de pensamento acerca das imagens é a complexidade e o caráter individualizado de seu processo interpretativo - apesar dos vieses distintos de análise de cada autor. Schopenhauer (2001) argumenta não ser possível falar de imagem sem falar de sua representação com o mundo. Para o filósofo as imagens não provam nada, é a vontade de cada um que vai definir como se enxerga determinada representação, "os acontecimentos do mundo só terão significado enquanto sinais reveladores da ideia do homem; eles não terão nenhum em si mesmos nem por eles mesmos" (SCHOPENHAUER, 2001, p. 200). Ao buscar aproximar a ideia de vontade de Schopenhauer (2001) com o conceito de percepção abordado por Merleau-Ponty (2003), 
o ver se revela como atividade individual, ressaltando a concepção de que cada um tem sua representação e percepção quando deparado com uma imagem.

Segundo Merleau-Ponty (2003), a percepção é um processo que inicia no olhar e que vai aos poucos determinando a verdade do indivíduo, onde ao captar as partes e juntá-las ao todo é que se compreende o que está sendo mostrado. Porém, essa compreensão é individual, "a própria coisa, já vimos, sempre é para mim a coisa que eu vejo" (MERLEAU-PONTY, 2003, p. 22). Ao mesmo tempo, o autor (ibidem, p. 15) menciona a existência de uma "camada profunda de 'opiniões' mudas, implícitas em nossa vida" ao se ver as coisas no mundo.

A comunicação transforma-nos em testemunhas de um mundo único, como sinergia de nossos olhos os detém numa única coisa. Mas tanto num caso como no outro, a certeza, embora inelutável, permanece inteiramente obscura; podemos vivê-la, não podemos nem pensá-la, nem formulá-la, nem erigi-la em tese. Toda tentativa de elucidação traznos de volta aos dilemas (MERLEAU-PONTY, 2003, p. 23).

A subjetividade que acompanha a mirada das as imagens é, portanto, inescapável. E, podemos afirmar, que as ambiguidades presentes nas variadas interpretações de uma imagem somente são reduzidas quando nos afastamos da riqueza da linguagem rumo às relações mais diretas entre mensagem visual e significado firmadas em sistemas de sinalização (em prol de um pragmatismo na tomada de decisões ao conduzir um veículo, por exemplo) ou logomarcas (que são expressões visuais do capital simbólico e financeiro de empresas). Dessa forma, alcançar uma "certeza”, um resultado binário: sim ou não, foi falta no lance ou não foi, permanece inatingível.

É natural que, quanto mais pessoas vejam algo, mais variadas sejam as interpretações. Nesse sentido, árbitros, narradores, comentaristas, jogadores, cada um terá a sua interpretação própria da imagem. Isto impossibilita alcançar aquilo que é chamado popularmente no futebol de "imagem clara", tendo em conta que nunca haverá uma unanimidade interpretativa apesar dos avanços tecnológicos da televisão, em razão da análise de uma imagem ser considerada um ato individual.

Avançando para além da ideia do ver, Bergson (2006) chama de inteligência os métodos utilizados para pensar e elaborar as imagens. Essa inteligência é constituída por 


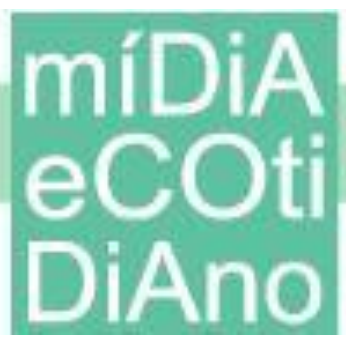

três funções: 1) perceber - apoderar-se de imagens infinitamente repetidas que são condensadas por nossos olhos, numa fração de segundo, pela visão de uma coisa única; 2) conceber - formar uma ideia geral, única e invariável; 3) compreender - encontrar nexos, estabelecer relações estáveis entre fatos que passam. Para que esse processo aconteça é necessário tempo para sua elaboração, quanto maior o tempo mais profunda a análise: “o tempo é aquilo que impede que tudo seja dado de um só golpe. Ele retarda ou, melhor, ele é retardamento. Ele deve, portanto, ser elaboração"(BERGSON, 2006, p. 106). Novamente, esse tempo varia conforme cada indivíduo. A relação que pode ser estabelecida com a análise das imagens e o VAR é que conforme o tempo passa e as imagens são repetidas, resultando na elaboração da percepção de cada um. No contexto esportivo, por exemplo, possivelmente em programas de mesa redonda - realizados após o encerramento do jogo - as percepções e intuições sobre os lances também se diferenciem, já que houve um tempo maior para uma elaboração. Essa reflexão contribui para um entendimento de que as divergências dos lances tendem a aumentar com o passar do tempo.

Ao afirmar que "o que vemos só vale - só vive - em nossos olhos pelo que nos olha", Didi-Huberman (1998, p. 29) também ressalta o poder do espectador sobre a imagem. $\mathrm{O}$ autor define duas maneiras de como as imagens podem ser vistas: por meio da crença, onde aquilo que eu vejo é o que eu acredito; e pela tautologia, usando a imagem como prova, onde se olha de acordo com "uma espécie de cinismo: 'o que vejo é o que vejo, e o resto não me importa"” (ibidem, p. 40). Essas duas formas fazem parte do que ele chama de dialética, onde ocorre um questionamento constante: é possível acreditar de fato em tudo que é visto? Existe uma certeza de que aquilo que é visto é verdade? Perdura assim um processo contínuo de incerteza impulsionado por ambas as percepções: tautológicas e de crenças. Logo, se torna possível discutir que as imagens não podem representar o real, conforme o próprio Didi-Huberman (2012, p. 208) argumenta: “A imagem em contato com o real - uma fotografia, por exemplo — nos revela ou nos oferece univocamente a verdade dessa realidade? Claro que não".

No questionamento do que seria o real, Badiou (2017) suscita a reflexão de pensar o real como uma hipótese, que, todavia, não apresenta o próprio real, que não pode ser comprovado, constituindo-o assim como uma imposição. Desse modo, o real se define como intimidação ou submissão que domina nossas experiências. 
Ou seja, por nos reconduzir ao fato de que nossa percepção, nosso encontro com o real, aquilo que tomamos por nossa espontaneidade livre e independente, tudo isso, na realidade, está estruturado de cabo a rabo pela figura do mundo tal qual ele é, ou seja, um mundo submetido ao imperativo do real como intimidação (BADIOU, 2017, p. 15).

Dentro dessa "ditadura de um conceito real por intimidação" (ibidem, p. 15), o filósofo relata a função do escândalo no mundo, destacando o esporte como um agente potencial na geração desses escândalos, devido a sua exposição pública significativa ostentando continuamente valores como esforço, lealdade, performance, sucesso merecido. Dessa forma, um escândalo vem a público "como a revelação de um pedacinho do real" (BADIOU, 2017, p. 15). O escândalo esportivo pode ser visto como um semblante, uma máscara, que pode ser considerado uma pequena parte do real.

Dessa forma, o real seria sempre algo que a gente desmascara, algo cuja máscara a gente arranca, o que quer dizer que seria sempre no ponto do semblante que haveria uma chance de encontrar o real, uma vez que é preciso também que haja um real do próprio semblante: que haja uma máscara, que ela seja uma máscara real. E assim chegamos à conclusão um tanto singular de que, em definitivo, todo e qualquer acesso ao real [...] sempre se dá quando uma máscara é arrancada, ato que, entretanto, se institui ativamente a distinção do real e o semblante, deve assumir também que existe um real do semblante, que há um real da máscara (BADIOU, 2017, p. 23).

A implementação do VAR, assim como o padrão único de transmissão dos jogos, permite inferir que repetições dos lances polêmicos são como essas "máscaras com um semblante real", consequentemente contribuem de algum modo para a instauração dos escândalos dentro da Copa do Mundo. A partir do momento em que as duas transmissões analisadas formulam diferentes hipóteses sobre uma única imagem supostamente real, esse real como prova passa a não existir. Segundo o autor (ibidem) "só há conquista do real ali onde há uma formalização - pois, se o real é o impasse da formalização, é preciso que haja uma formalização".

Para melhor elucidar sua reflexão, Badiou (2017) utiliza a matemática como exemplo da aplicação de sua teoria. Ao contar, multiplicar, adicionar etc. estamos no interior da formalização matemática, onde ao concluir qualquer cálculo, a expectativa 


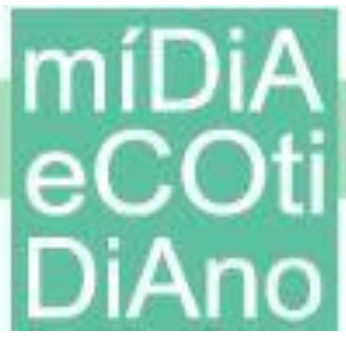

final é sempre encontrar um resultado expresso por um número. Entretanto, os números são infinitos, e o infinito não é um número, ele inexiste na aritmética. Assim, o real da aritmética exige a admissão de algo inacessível que quebra com sua formulação, sendo assim o infinito surge como um símbolo que representa números.

[...] aquilo que a formalização torna possível - a saber, no nosso exemplo, calcular a partir de números - só é possível pela existência implicitamente assumida daquilo que não pode se inscrever nesse tipo de possibilidade. Trata-se, portanto, de um "ponto de pensamento" que, embora condenado a permanecer inacessível para as operações que a formalização torna possíveis, não deixa de ser a condição última da formalização (BADIOU, 2017, p. 30).

Ou seja, ao instituir formalidades que busquem expressar o real, constata-se que existem elementos que não podem ser encaixados nesses modelos, o que de algum modo mostra que o real por completo não pode existir. A partir deste ponto de vista, é possível considerar os replays e o próprio VAR como constituintes do processo de formalização da busca de uma possível "clareza nos lances do futebol". Ao final, conforme já observado, esse processo se mostra impossível, visto que não existe um resultado único - um consenso de que foi pênalti ou falta, por exemplo. Ao assumir essa postura se declara que o impossível existe, estando aí o "gesto fundamental de conquista do real" (BADIOU, 2017, p. 34). Sendo assim, por mais imagens que se tenha para representar o real, elas nunca conseguiram cumprir esse objetivo por completo, logo elas não podem ser consideradas reais, e consequentemente, no caso da análise dos lances apresentados, conclusivas ou "claras".

\section{Considerações finais}

Analisar e interpretar imagens pode ser considerada uma atividade extremamente complexa. O esporte, mais especificamente o futebol e a Copa do Mundo, por sua cobertura mundial, conforme já enfatizou Badiou (2017), suscitam muitas discussões e "escândalos". Gastaldo (2005, 2009), ao analisar a relação entre futebol, Copa do Mundo e os processos de midiatização, ressalta o quanto as imagens transmitidas durante as partidas influenciam e permitem a construção de significados por parte da mídia. A implementação do VAR de alguma maneira amplificou o poder e a subjetividade 


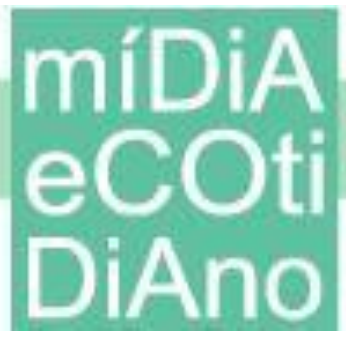

que as imagens têm. Analisando um recorte durante a Copa do Mundo 2018, seja dentro de campo com depoimentos de árbitros, jogadores, técnicos, ou mesmo fora dele em manifestações de entidades, equipes, mídia, não foi raro observar dissonância, até mesmo completa discordância, entre as mesmas imagens visualizadas por todos. Ao buscar um entendimento dos motivos que levam a esse processo foi possível vislumbrar um caminho de compreensão relacionando o desenvolvimento desses acontecimentos com reflexões filosóficas estabelecidas por pensadores clássicos.

Em entrevista ao portal Metrópoles (2018), Arnaldo Cezar Coelho, primeiro árbitro sul-americano a apitar uma final de Copa do Mundo e comentarista de arbitragem da Rede Globo desde 1989, declarou que "nunca viu um número de erros dos árbitros tão grande como agora". Para o ex-árbitro, os juízes da Copa estão terceirizando as decisões para o VAR, ficando assim "robotizados". Ao seu ver "a tecnologia ajuda o futebol em casos se a bola entrou ou não ou na linha de impedimento. A imagem é seca e fria em casos que não são interpretativos".

As dificuldades e morosidade na implementação do árbitro de vídeo já denotam os cuidados que a análise de imagens demanda. Muitos foram os testes com VAR realizados pela FIFA, de forma oficial e não oficial, antes da sua utilização naquele que pode ser considerado o principal evento da entidade. Mesmo com a insistência em testes e aprimoramentos as divergências existiram desde o primeiro uso, e possivelmente não cessarão. Isso pode acontecer pois em casos literais como se a bola entrou ou não, foi dentro ou fora da área, existe uma objetividade permitida por uma referência estática linha do gol ou lateral, linha digital aplicada para mostrar posições de impedimento (FIFA, 2018c) - reduzindo consideravelmente a margem de interpretação, como a própria entidade cita: "A equipe do VAR comunica-se com o árbitro somente em casos de erros claros e óbvios ou por sérios incidentes perdidos"5. Contudo, grande parte dos lances esportivos são interpretativos e subjetivos, e durante as partidas da Copa o VAR acabou sendo utilizado também em nesse tipo de acontecimento.

\footnotetext{
5 Tradução dos autores para: "The VAR team communicates with the referee only for clear and obvious mistakes or serious missed incidents" (FIFA, 2018c).
} 
Esses processos interpretativos podem ser analisados de diferentes maneiras a partir de diversos pensadores clássicos que refletem acerca das teorias das imagens. $\mathrm{O}$ que continuamente se repetiu nas reflexões teóricas apresentadas foi o fato da análise de imagens ser um ato individualizado. É interessante observar que de algum modo a própria FIFA (2018e) destaca o caráter interpretativo e individualizado presente na percepção de imagens ao explicar o VAR com expressões como: "VAR recomenda ao árbitro que uma decisão/incidente deve ser revisada", "O vídeo é revisto pelo VAR, que aconselha o árbitro via fone de ouvido o que o vídeo mostra"7, "O árbitro decide rever o vídeo ao lado do campo de jogo antes de tomar a ação/decisão apropriada"8. Isso nos leva a entender que existem interpretações das imagens realizadas por diferentes membros da equipe de arbitragem, "recomendando" e "aconselhando", todavia, é o árbitro principal que vai ter a decisão/interpretação final.

O que foi possível observar na busca das relações entre autores clássicos e a divergência de interpretações é de que, conforme identificado nas transmissões, não existe uma "unanimidade perceptiva". O processo de visualização, percepção e concepção imagética é único, particular, varia para cada pessoa, sendo influenciado por inúmeros fatores. Ao tentar obter uma "formalização do real" por meio da análise de imagens, o que tem se observado é que o alto índice de divergências existe, que possivelmente não será evitado com o árbitro de vídeo, o que permite inferir que esse real buscado nas imagens esportivas talvez nunca exista. Durante o programa Seleção SporTV (2018), ao discutir o VAR, os componentes da mesa debateram sobre as percepções, interpretações e subjetividades das imagens. Ao final do vídeo o jornalista esportivo André Rizek, ao listar as diferentes opiniões dos comentaristas sobre os lances polêmicos, contribui na consideração de que a imagem real no futebol talvez nunca vá existir ao argumentar que: "[...] a gente adora discutir arbitragem. Por que o VAR é também um sucesso? Porque a gente continua discutindo arbitragem com o VAR", ele conclui

\footnotetext{
6 Tradução dos autores para: "[...] the VAR recommends to the referee that a decision/incident should be reviewed" (FIFA, 2018e).

7 Tradução dos autores para: "The video footage is reviewed by the VAR, who advises the referee via headset what the video shows" (FIFA, 2018e).

${ }^{8}$ Tradução dos autores para: "The referee decides to review the video footage on the side of the field of play before taking the appropriate action/decision" (FIFA, 2018e).
} 


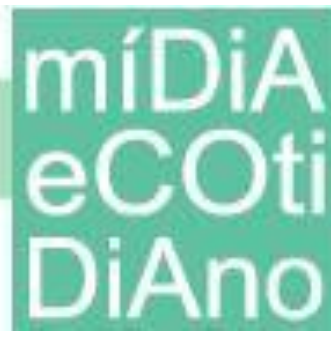

dizendo: "O VAR não matou o prazer que todo mundo tem quando discute futebol de discutir arbitragem. Ele tornou a discussão diferente".

As imagens de lances esportivos polêmicos, assim como as análises do árbitro de vídeo, nunca serão claras e conclusivas, sendo esse possivelmente o ponto que torna o esporte apaixonante e, ao mesmo tempo, que impede que se entenda que o real efetivamente não existe. Talvez a beleza da análise das imagens esteja exatamente nesse paradoxo: ao buscar um real inexistente, quanto mais se procurar mais distante se fica da conclusão final. Essa parece até agora ser a única "imagem clara" que se consegue encontrar.

\section{Referências}

BADIOU, Alain. Em busca do real perdido. Belo Horizonte: Autêntica, 2017.

BERGSON, Henri. O pensamento e o movente: ensaios e conferências. São Paulo: Martins Fontes, 2006.

CRARY, Jonathan. Suspensões da percepção: atenção, espetáculo e cultura moderna. São Paulo: Cosac \& Naify, 2013.

DIDI-HUBERMAN, Georges. O que vemos, o que nos olha. São Paulo: 34, 1998.

. Quando as imagens tocam o real. (nov. 2012). Pós: Revista Eletrônica do Programa de Pós-Graduação em Artes da Escola de Belas Artes-UFMG, Belo Horizonte, v. 2, n. 4, p. 204219. Disponível em: https://www.eba.ufmg.br/revistapos/index.php/pos/article/view/60/62. Acesso em: 7 jul. 2018.

ESPN. (6 fev. 2018). Clubes aprovam grama sintética e venda de mando no Brasileiro, mas vetam árbitro de vídeo. ESPN. Disponível em:

http://www.espn.com.br/futebol/artigo/_/id/3955168/clubes-aprovam-grama-sintetica-e-vendade-mando-no-brasileiro-mas-vetam-arbitro-de-video. Acesso em: 3 jun. 2018.

EXAME. (29 jun. 2018). Árbitro de vídeo foi usado 335 vezes na primeira fase da Copa. EXAME. Disponível em: https://exame.abril.com.br/estilo-de-vida/arbitro-de-video-foi-usado335-vezes-na-primeira-fase-da-copa. Acesso em: 2 jun. 2018.

FIFA. (9 jun. 2018a). 2018 FIFA World Cup Russia ${ }^{\mathrm{TM}}$ International Broadcast Centre opened in Moscow. Fifa.com. Disponível em: https://www.fifa.com/worldcup/news/2018-fifa-world-cuprussiatm-international-broadcast-centre-opened-in-moscow. Acesso em: 2 jun. 2018.

. (3 mar. 2018b). REPLAY: IFAB comes to landmark decision about VAR. Fifa.com. Disponível em: https://www.fifa.com/about-fifa/news/y=2018/m=3/news=coming-soon-pressconference-following-the-ifab-annual-general-meeting.html. Acesso em: 2 jun. 2018.

. (2018c). VAR at the 2018 FIFA World Cup. Fifa.com. Disponível em: https://footballtechnology.fifa.com/en/innovations/VAR-at-the-World-Cup. Acesso em: 2 jun. 2018. 
. (3 mar. 2018d). VAR discussed at IFAB media briefing. Fifa.com. Disponível em: https://www.fifa.com/about-fifa/news/y=2018/m=3/news=var-discussed-at-ifab-mediabriefing.html. Acesso em: 2 jun. 2018.

GASTALDO, Edson. A recepção coletiva de futebol midiatizado: apontamentos etnográficos. In: ENCONTRO ANUAL DA ASSOCIAÇÃO NACIONAL DOS PROGRAMAS DE PÓSGRADUAÇÃO EM COMUNICAÇÃO, 14., 2005, Niterói, Rj. Anais [...]. São Paulo: Compós, 2005.

. Ritos da nação: uma vídeoetnografia da recepção coletiva da Copa do Mundo no Brasil. Revista Brasileira de Ciências do Esporte. Campinas, SP, v. 31, n. 1, p. 209-222, set. 2009.

GAÚCHA ZH. (19 set. 2017). Árbitro de vídeo "engatinha” na Europa com um misto de esperança e preocupação. Gaúcha ZH, Porto Alegre. Disponível em: https://gauchazh.clicrbs.com.br/esportes/brasileirao/noticia/2017/09/arbitro-de-video-engatinhana-europa-com-um-misto-de-esperanca-e-preocupacao-9906079.html. Acesso em: 3 jun. 2018.

KRACAUER, Siegfried. Teoría del cine: La redención de la realidad física. Buenos Aires: Paidós, 2002.

MERLEAU-PONTY, Maurice. O Visível e o Invisível. 4. ed. São Paulo: Perspectiva, 2003.

METRÓPOLES. (29 jun. 2018). Para Arnaldo Cezar Coelho, "estão robotizando a arbitragem com o VAR". Metrópoles. Disponível em: https://www.metropoles.com/esportes/futebol/paraarnaldo-cezar-coelho-estao-robotizando-a-arbitragem-com-o-var. Acesso em: 3 jun. 2018.

SALGADO, Diego. (10 jun. 2014). Erros de arbitragem marcam história das Copas do Mundo. O Estado de São Paulo. Disponível em: https://esportes.estadao.com.br/noticias/futebol,errosde-arbitragem-marcam-historia-das-copas-do-mundo,1509074. Acesso em: 2 jun. 2018.

SCHOPENHAUER, Arthur. O mundo como vontade e representação. Rio de Janeiro: Contraponto, 2001.

SPORTV. (29 jun. 2018). Comentaristas debatem o uso da câmera lenta em análises do VAR. SporTV. Disponível em: https://sportv.globo.com/site/programas/selecaosportv/noticia/comentaristas-debatem-o-uso-da-camera-lenta-em-analises-do-var.ghtml. Acesso em: 10 jul. 2018.

VEJA. (14 dez. 2016). Deu ruim para a Fifa: estreia desastrosa do árbitro de vídeo. Veja. Disponível em: https://veja.abril.com.br/esporte/estreia-de-arbitro-de-video-gera-confusao-nomundial-de-clubes. Acesso em: 3 jun. 2018. 